\title{
Native Tradition and Changing Market Dynamics: The Future Sustainability of Hajo and Sarthebari Metal Crafts
}

\author{
Lakhimi Jogendranath Chutia ${ }^{1}$ \& Mrinmoy K Sarma ${ }^{2}$ \\ ${ }^{1}$ Research Scholar, Tezpur University, Assam, email: clakhimi@yahoo.co.in \\ ${ }^{2}$ Professor, Tezpur University, Assam, email: mrinmoy@tezu.ernet.in
}

\begin{abstract}
The article deliberates over the issue of sustainability of traditional crafts from the economic as well as tradition point of view. In the age of global competition when the world has become a small trading community, handicraft artisans constantly compete with machine made products and struggle for the sustenance of their age old traditional industries. The traditional brass and bell metal sector of Sarthebari and Hajo in Assam is going through a similar fate. Changing functional requirements and aesthetics orientation of modern customers are pressing artisans to modify certain traditional features of the crafts and innovate according to market demand. In addition to this, unrestricted flow of imported metal items also offers tough competition to the indigenous sector. Artisans complying with existing needs of customers, comparatively, do well in economic terms than those producing age-old products. As noticed, artisans also seem to continue the craft in future and encourage their kith and kin to undertake the occupation, since they find it a reliable income source. Meanwhile, change in archaic design and make of metal items raises the issue of sustainability of tradition. However, it is important to understand if harping on to tradition overlooking economic sustainability of producer of the craft can ensure the sustainable growth of the sector. The paper thus aims to highlight the present scenario of the industry and its future scope for sustainability by taking into consideration the artisans' and market viewpoint. It extends suggestions based on the information gathered from the market and producer to ensure sustainability of the art and the artisan.
\end{abstract}

Keywords: Sustainability, traditional, economic, brass and bell metal crafts, artisans, Assam

\section{Introduction}

It is obvious that the notion of sustainability is imperative for crafts sector as it has been a source of income for traditional artisanal families. Sustainability, though an easy word to explain, yet its meaning is too broad to entertain. As making skills transfer from parents to children, craft activity can readily help generate income (Chotiratnapinun, 2009). On the other hand, dilution of the traditional components of the craft like design and aesthetics takes place. Artisans, in lure of producing more in less time, compromise on many production aspects like quality and and design. They alter the old designs foregoing

(c) AesthetixMS 2016. This Open Access article is published under a Creative Commons Attribution Non-Commercial 4.0 International License (http://creativecommons.org/licenses/by-nc/4.o/), which permits non-commercial re-use, distribution, and reproduction in any medium, provided the original work is properly cited. For citation use the DOI. For commercial re-use, please contact editor@chitrolekha.com 
the quality that their ancestors religiously maintained. The loss in traditional components also arises due to artisans' compliance to contemporary aesthetic tastes, which in turn, give rise to issues of authenticity. The connection between craft and economic sustainability vis-à-vis the traditional value, in changing market dynamics, is rather complex. According to Crafts Council of India report (2011), the craft industry faces the arguments of economic sustainability of the craftsmen as well as the sustainability of the craft and its authenticity itself.

Authenticity, as a term, is construed and re-construed by many scholars of art (Shiner, 1994; Rowlands, 2002; O'Connor, 2012). Researchers like Clifford describe authenticity as something that never changes (cited in Ballengee-Morris, 2002:241). Minca and Oakes, on the other hand, mention that authenticity evaporates as and when it is searched (2006). Even some argue that art objects and art itself should remain 'unaffected by capitalist relations and market constraints' to rightfully preserve its native iconography and social meanings (Wolff, 1981). Allowing art to grow into commercial replica merely makes it a hollow image of the past without any substantial spiritual content (LaDuke, 1981). Waterbury (1989) describes how embroidered blouses in San Antonino, Mexico lost its long held symbolic significance. Similarly, hinggi textile of Sumba, Indonesia with new figures as well as motifs (Anas, 2005:116 quoted in Howard, 2006:47) and bul-ul and kinnahhu wood carving, considered as religious paraphernalia in Philippines, became disassociated from its original meaning and lost its authenticity, once it got commoditized (Tolentino Jr, 2012). Thus, relegating traditional crafts to the status of mere art, through visual changes, juxtapose such items as fakes (Shiner, 1994).

It is often forgotten that crafts, apart from being cultural grace of a society, are also an income source for the artisan community. The prison house of authenticity sees contamination in every little change that otherwise is also economically helpful for its continuity (Rowlands, 2002). While enveloping authenticity and sustainability of traditional art forms, researchers often forget about economic sustainability of the craftwork. In fact, cultural objects, when it is more related to economic sustenance, proposing strict abidance to local style, design and technique components is rather a misguided construct as cultural advances and exchanges are a continuous process (Shiner, 1994) in an economic sphere. Unless there is demand for craft objects and artisans benefit economically, artisans are liable to surrender tradition. Trade of indigenous pottery of Catawba valley in North Carolina (Blumer, 2004) and commercialization of ritual Mithila wall paintings of Bihar are enduring examples of preservation of tradition through economic sustainability of artisans (Wilkinson-Weber, 2004). Seen through many examples, folk products are salvaged through its commodification as it brought renewed interest among indigenous craftsmen to pursue it 
(Berma, 1996) for families' economic sustenance (Howard, 2006). Demand for folk arts as souvenir objects in regional and international markets fuelled production of contemporary items made from traditional quilted pieces in Pennsylvania (Boynton, 1986). Similarly, sarape textile made from wool in Oaxaca, Mexico saw increased demand as home furnishing item once hybridized (Popelka and Litrell, 1991). The traditional dice mat known as pasa-pali, is increasingly pursued as wall hanging today though in modern forms with new color combinations and design forms. This helped sustain its crafting among artisans of Orissa (Mohapatra, 2005; Mohapatra, 2008). In a market sphere, hence, authenticity or otherwise, in cultural objects, cannot be unilaterally summarized as detrimental or beneficial without taking into consideration the opinion of its producers. If one is to agree to researchers like Reisinger and Steiner, authenticity is irrelevant (2006) in the post modern society (Terziyska, 2012).

The traditional brass and bell metal crafts of Sarthebari and Hajo face similar issues related to economic sustainability of the artisans and its impending effect on tradition and sustainability. Artisans in haste to produce more to earn more are giving up the traditional motifs exclusively carved on the archaic products. Instead they engrave elaborate motifs but less complicated ones to manage time and increase output. Doing so has resulted in cessation of many intrinsic patterns and structural forms. Many beautiful pieces have also gone into oblivion and are produced no more. Artisans are also giving into the demand of the contemporary customers by compromising their tradition. Undoubtedly, the demand for a product brings change in style and design and offer new market opportunities to producers. However, at the same time, it also offers a great threat to sustainability of tradition (Kapur \& Mittar, 2014). Again, if not modified to be fit for the consumer driven market many crafts face premature extinction. It is thus a battle between tradition and modernity in the face of economic sustainability (Soteriou, 1998). Other than that, the changing equations of the craft trade in the middlemen saturated market is another reason for this designed imbalance between tradition and economic sustenance. The unchecked offloading of cheap, shining machine made metal products in local markets from places other than Assam, and artisans' inability compete with his hand tools complicate the equation further. Without any direct access to the ultimate customer groups, artisans can do nothing but comply with middlemen's instructions. The vicious cycle of economic degeneration with simultaneous dissipation of cultural aura thus continues. This article aims to deliberate upon the notion of economic sustainability of the brass and bell artisans as well as the sustainability of crafting tradition. 
4 | The Chitrolekha Journal on Art and Design, Vol. 1, No. 2, 2017

\section{Research Methodology}

The study is conducted at Sarthebari of Barpeta and Hajo of Kamrup districts in Assam in the period between 2014 and 2016. The research adopted both quantitative and qualitative methods. Sample pictures of old products were obtained from old product collectors (individual households and persons dealing with trade of old items) and museums. Individual objects and designs were studied to understand the structural and design modifications in the craft. A comparison with the new brass and bell metal products currently produced by the artisans was made to study the difference between the old and the new and understand the sustainability of the design, the form and the craft practice. Apart from that, questionnaire cum schedule as an instrument was adopted and administered to 140 artisans, 70 each from brass and bell metal segments based on convenience. Their perception regarding the income sufficiency from the craft activity was ascertained to understand its economic sustainability.

For gathering information on sustainability of the craft in the market place, individuals engaged in selling and marketing of the craft were approached. Qualitative in-depth interviews were taken to read their views regarding existing market demand and opinion on modification needs in the craft objects produced by the artisans. It also utilizes secondary data sources obtained from books, reports and other available documents.

\section{A Historical Reflection of the Brass and Bell Metal Industries of Sarthebari and Hajo}

The bell metal industry of the state of Assam dates back to 321 B.C to 185 B.C to the times of Mauryan period (A. Deka, 2012). Legends state that King Bhaskar Varman sent a pair of bhortal and several kinds of drinking utensils to King Harshvardhan of Kannauj (Baishya, 1989; Baruah \& Choudhury, 1999). Later, the craft received patronage of the Ahom ${ }^{l}$ kings and nobility and flourished so well that few products made by the artisans were sent to Buddhist countries like China, Tibet, Burma, Bhutan and Nepal (Baruah \& Choudhury, 1999). The exports continue till date (field survey). In domestic circuit, bell metal items also have market in Manipur, Bihar, Jalpaiguri (in West Bengal) and Arunachal Pradesh (Kalita, 2007). Written records of the $14^{\text {th }}$ century provide ample evidence of Sarthebari's association with bell metal craft (Deka, 1995). Some very well known names like that of Pushparam Kahar exist in the bell metal history of Sarthebari. He is known to have created exquisite products like bhogjara, xorai, nakpheti bota, tema bota, jat kahi, dug dugi lota and many more (Tamuli, 2009). His hand-made pikdan (spittoon) is said to be

\footnotetext{
${ }^{1}$ Ahoms were the people from the Shan dynasty of present day Myanmar. Led by prince Sukaphaa they established the Ahom kingdom in Assam (1228 A.D to 1826 A.D.) for a period of almost 600 years.
} 
displayed in the British Museums (ibid). The bell workers produced all necessary household utensils out of this alloy.

Brass is also an important cottage industry in Assam with its roots linked to the Muslim invasion in the $16^{\text {th }}$ century A.D. According to historical records, geographical proximity of Kamrupa (a name synonymous to Assam in history) to Mohammedan ruled Bengal led to many invasions of the province of Kamrupa. Many such expeditions resulted in vain, but a long drawn battle at Sariaghat between the Mughals and Ahoms led to the settlement of some Muslim soldiers who brought with them many brass works (Bose, 1989; Das, 1968; Patra \& Vachani, 2012). Hajo became the stronghold of these soldiers who later came to be called as the Moria community. the brass works they produced were basically utilitarian ones like tou, kahi, bati, ghati, kalasi, kharahi, soria and spoons of various types like heta, sepeta heta, samus, bor heta, phuta loga heta, etc (Das, 1968). However, one cannot say with surety that brass metal never existed prior to the immigration of Mohammedan warriors. Other than the Morias, brass metal particularly known as xorai shilpa flourished among some Hindu people at Hajo and Sarthebari (Deka, 2012: 92). According to reports, it started circa 1850 A.D and was limited to only the villages of Baniyakuchi and Haldhibari (Deka, 2012). However, the family tree of the artisans suggests settlement of the brass and bell metal artisans in the region sometime in the $14^{\text {th }}$ century (Ghosh, 2016). In Allen's record, temporary visitors from Sarthebari in Kamrup produced brass metal items like kasli, gagari, tema-temi (small boxes to carry betel-nuts and lime), xorai, etc (1905). Dunari was a very special item with decorative lid used in marriages (Das, 1968).

Brass and Bell Metal Products and its importance in socio-cultural and religious settings in Assam

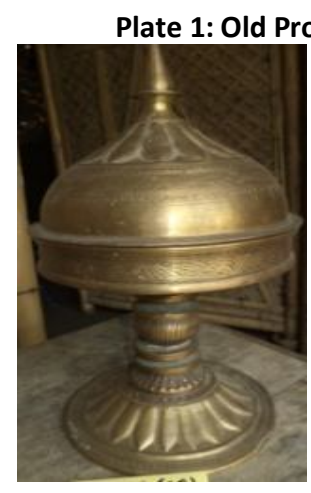

a.Xorai

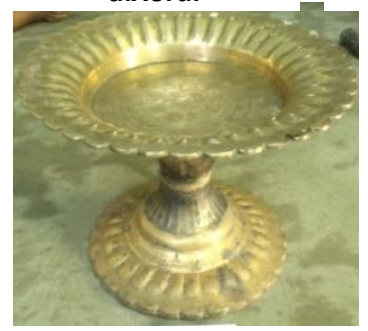

c.Bota

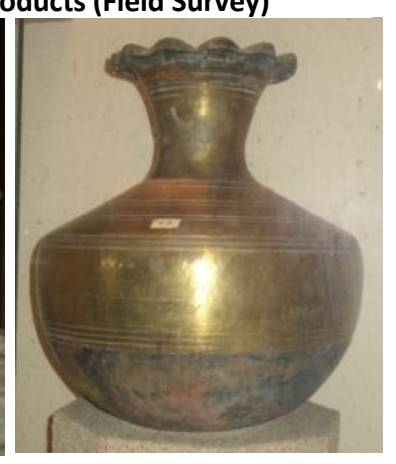

b.Kalah

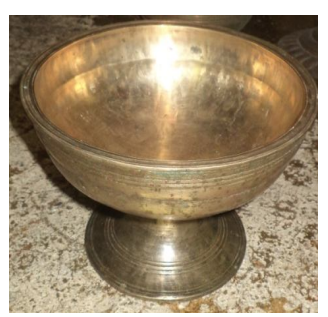

d. Ban-bati 
Bell metal objects quintessentially represent the socio-cultural tradition of Assam. The metal known as $k a h$ is an alloy of $22 \%$ tin and $78 \%$ copper. Its importance is such that Assamese bride, cutting across all religious and caste groups, are compulsorily gifted with a set of traditional bell metal objects to be carried to the new family. Similarly, brass metal objects are also core to Assam's tradition. Known as pital in Assam, it is again composed of a mixture of copper at $70 \%$ added to which is $30 \%$ zinc. Pital objects are equally valuable in socio-religious atmosphere of Assam. Metal utensils of Assam were very much influenced by South-East Asian cultures (Sarma, 1989). The Tai influence probably gave in to the use of stand under each bowl and plate to make it resemble to goblets and chalices (Das Gupta, 1982). 'Ban' as a prefix for each bowl and plate is the result of this influence (ibid).

Elaborate account of metal objects is obtained in all records of Allen (1905), Gait (1896) and Hutchinson (1909). Several books and research works by authors like Das (1968), Das-Gupta (1982), Tamuli (2009), Deka (2012) and Kalita (2007) also mention about some of the old products still produced in Hajo and Sarthebari. Some of the important brass and bell metal utensils of Assam since medieval times, as documented, are tow (a washbowl for edibles), bati (bowl), ban-bati (a bowl with a stem), ban-kahi (meal dish with a stand), xorai (dishes mounted on a stand used to hold offerings to deities), bhogjara (ewer), gosa (a lamp with a stand), kahi (dish for meals), lota (small vessel to keep liquid), bota (flat circular tray with a stand to offer tamul-paan ${ }^{2}$ ), tema-temi (box to carry betel nut and lime), pikdan (spittoon), tal (cymbal), ghati (small pot to hold water), berha (tripod), soria (a kind of wash bowl), khorahi (similar to tow but with many holes) and kalah (water carrying vessel). Several other types of daily use items like heta (ladlespoon), thalas (large meal preparing dish as well as dish to keep sweets in temples), milking vessel known as karla, and other religious items like nagara (drum), Kalasi (used in temple to pour water on deity drop by drop; fixed kalasi is also mounted on temple top), etc. were also produced.

\section{A Brief Discourse on Earlier Style, Structure and Designs on Metal Products:}

Craft production in earlier times, as it understood from field survey, was more of a leisure activity. Craftsmen produced items primarily for personal consumption and sold some surplus when required. Since quantity mattered less, quality was more defined. Craftsmen enjoyed producing intricate design patterns to beautify the external dimensions of the craft object. The salient features of the motifs were the intensity of the chisel marks and

\footnotetext{
${ }^{2}$ Tamul-pan is an offering of areca nut and leaves given to guests as a sign of welcome. This is an ancient practice followed since time immemorial in Assam.
} 
the embossed patterns. Artisans chiseled every accessible surface in varieties of dhekia (ferns), lata (creeper), phul (flower with 3 or more petals) and pankata (leaf). Fish scale, slant lines and dot within circle on the entire peripheries were common designs on phulam (decorative) kahi, bati, xorai, kalah and bota. These designs were also repeated alternately to create aesthetic impressions on the objects. The spacing between the chiseling marks was narrow to give it a very refined look. On the embossing front, the denting on the backside of the metal was done in a way to create prominently raised patterns on the front. These embossing took shapes of tribhuj (triangle), arch, petal and horizontal bars tapered at the ends into semicircular forms. The embossed patterns were carved mostly on the base, centre and peripheries of the objects. The depth of the curvatures (pai in local term) on the mouth of kalah and periphery of bota and kahi throughout the circumference remained sharply marked. In bojorowa (plain) kahi, bati, and bota designs were not chiseled but khap-kata (plain line chipped in one or two layers) remained a part.

\section{Present status of the crafts}

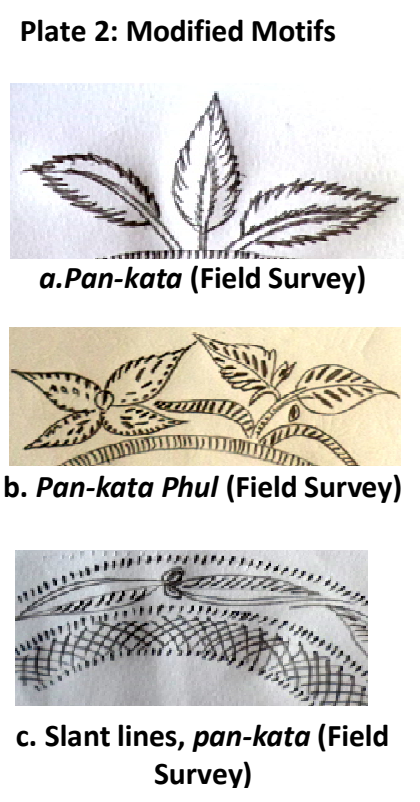

Primordial metal objects that define the metal craft culture of Sarthebari and Hajo are still in production. However, with time, economic need, motivated artisans to commercialize their crafts and focus on quantity. Certain structural modifications and change in baseline designs and styles started to evolve as soon as the motive of production moved from generating little surplus to as much surplus as possible. Many of the medieval products have ceased to exist today due to its lack of use, perhaps even due 
to artisans' loss of the knowledge of producing it. Some of the most beautiful creations of the yesteryears in bell metal like hophura bota, tema bota, jari lota, dugdugi lota, jat kahi, owkhulia bota and others are no more produced in present times. Either the craftsmanship is lost or the artisans simply cannot spend time producing exquisite items that do not have any demand to commensurate the labour and expertise needed to produce them.

Realizing the obscure but crucial situation of the crafts sector, the article reflects upon the modifications taking place in the metal crafts of Sarthebari and Hajo. It takes into consideration the market related information and present socio-economic aspects of the artisan society. Based on these data it offers suggestions to bring the brass and bell metal artisans out of the conundrum of choosing between economic sustenance and cultural sustainability. As reported by McKean, it is observed that understandable tradition with palatably aesthetic features can retain the idealness in crafts.

\section{Modification in Designs and Motifs}

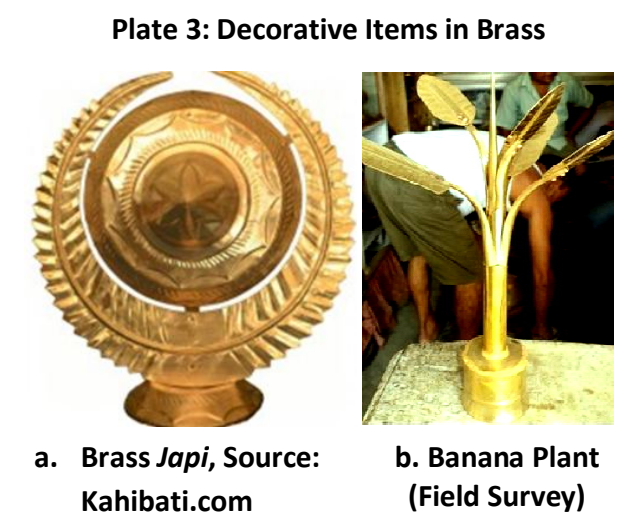

Items like kahi, bati, ban-bati, kalah, etc. are produced mostly, for the local customers of Assam. Some products like varieties of bhutia tal or cymbals known as pasang, bheri and cimeng, dophla kahi- bati (large meal dishes in bell metal), etc. are yet developed for customers of adjacent states like Arunachal Pradesh, and neighbouring countries like Nepal and Bhutan with little or no modification at all. However, some of the designs produced on the phulam items have modified to a great extent. The pan-kata, slant lines, fish-scale and dot within circle patterns, though replicated, have lost the intricacy in present forms. The narrow spacing that remained the primary charm of the designs has been increased to cover more surfaces in less time. Several modifications can be seen in pan-kata with new and bigger leaf structures and flower motifs are also enlarged. Other than these baseline motifs, heterogeneous motifs like pokhila (butterfly), mayur (peacock) and folded hands are carved. Gigantism in designs is a new feature. Trays, 
which are new addition to the product line in brass as well as bell metal items, have exquisite designs of flower vases, mayur on tree, dancing mayur, nartaki (dancing girls),

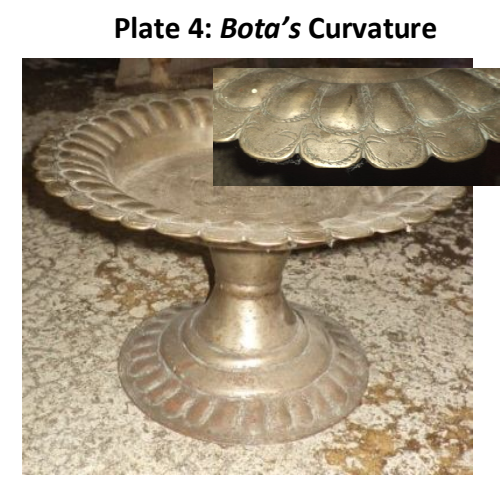

a. 80 year old bota (Field Survey)

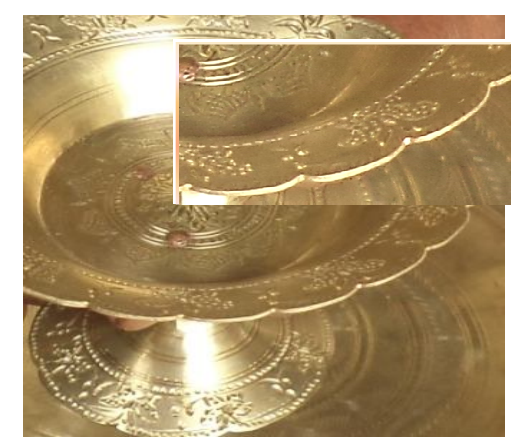

b. Bota new (Field Survey)

swimming ducks, etc carved on its surface. Letter inscriptions such as welcome and namaskar (a form of greeting in India) have also been in practice since the past 35 years. The designs have become more elaborate but gigantism and broad spacing of the designs has reduced the intricacy found in the earlier forms. The simplicity in designs is mostly practised for its easy chipping and time saving in a competitive and calculative world. Similar to chipping, the denting has also lost its original aura. The embossed patterns are not very prominently raised along the pais. Curvature depths of the pais along the mouth and periphery of the objects have also been made shallow. Reasons cited by artisans are the use of light weight metal sheets and dearth of time in order to produce more quantity for economic sustainability. Besides this, women customers also prefer shallow curvatures as it facilitates easy cleaning.

\section{Structural Modifications and Innovation in Metal Crafts}

Some inconspicuous structural changes have taken place in the metal objects for its suitability in the present market. Ban-batis are slightly modified to make it look like a cup rather than a bowl with a stand while extra knots are added to the xorai stand to increase 


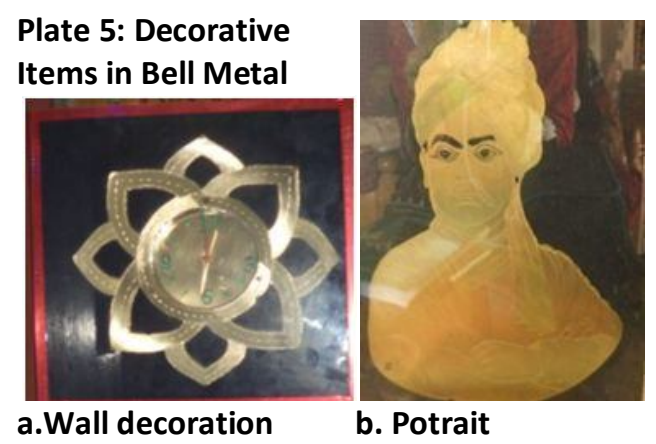

its aesthetics. Miniaturization is not a new tendency among artisans. However, it was more an artistic pursuit among yesteryear craftsmen. Crafters maintained the elegance of structure and designs in the miniaturized objects as found in the primary prototypes. It is, however, overtly practised today particularly in tow, khorahi, bota and xorai to suit the aesthetic needs of the modern customers. Bell and brass metal objects are used more as gift items for marriages, celebrations like annprasanna (feeding of first solid food to a new born) and birthday parties. Small replicas are also used as souvenirs and presents in institutional celebrations. Artisans have enhanced the features of gosa (lamp with a stand) by including more lamps, flowers and leaves to quell the requirement of customers for aesthetics in devotion. Traditional items are used as decorative objects, which rendered changes in design and forms. Besides these, new items are also added by young artisans to increase the product line. Metal jewellery, greeting cards, trophies with logo, wall decorations like brass japis (a kind of head gear originally made in bamboo), portraits, key chain, piris plates (dishes based on the concept of paper plates for use as saucer), etc. are innovated. Artisans of Hajo and Sarthebari have been modifying their products to stay economically sustainable in the local markets flooded by machine made light-weight and miniaturized replicas from places like Moradabad (in Uttar Pradesh). These external market forces in the form of inexpensive and decorative objects have led artisans of Assam to spontaneously introduce modifications and innovations.

\section{Economic Sustainability of the Artisans}

In order to ascertain sustainability of a traditional craft, the economic sustainability of the producer households is crucial to be investigated. The metal craft pursued in this study, as explained in earlier sections, is found to have undergone many modifications. Based on this data from field, artisans are categorized into three groups according to the craft genres they produce: Conventional metal craft producers (artisans producing the traditional crafts as their forefathers with little or no modification at all), Decorative items producers (artisans producing innovative crafts) and artisans producing both types. While brass metal artisans are found along all three groups, bell metal artisans are found 
to produce either conventional craft or decorative crafts. Artisans' were also asked to respond to question seeking information on degree of change introduced in the craft with respect to design, style, structure and form. The responses for the change introduced were measured as: None, Slight, Considerable and Great.

Profiles of respondent artisans on the craft they produce are presented in Table 1 . It is found that majority of the artisans produce only conventional products. Only $7.9 \%$ of the respondents are found to produce decorative craft objects. On exploring the reason behind this lean percentage of artisans in the segment, it was found that artisans find it difficult to enter the decorative craft producing section due to fear of losing grounds in their already established conventional craft market category. Artisans avert risking their regular income flow by experimenting with decorative crafts. Apart from that, lack of knowledge about market demand, unpredictable customer demand and lack of training on molding innovative products are also said to be the reasons for this aversion. Also, intermediaries like local mahajans (wholesale buyers of finished craft items and supplier of raw materials) find it convenient to buy from few artisans who are already producing decorative crafts,

\begin{tabular}{|l|l|}
\hline \multicolumn{2}{|l|}{ Table 1: Details on Craft Production } \\
\hline $\begin{array}{l}\text { Artisan groups based } \\
\text { on Craft Genres } \\
\text { Produced }\end{array}$ & Count (\%) \\
\hline Conventional (C) & $113(80.7 \%)$ \\
\hline Decorative (D) & $16(11.4 \%)$ \\
\hline Both & $11(7.9 \%)$ \\
\hline Total & $\mathbf{1 4 0}(\mathbf{1 0 0} \%)$ \\
\hline \multicolumn{2}{|l|}{} \\
\hline Degree of Change & Count (\%) \\
\hline None & $65(46.4 \%)$ \\
\hline Slight & $\mathbf{2 0}(14.3 \%)$ \\
\hline Considerable & $36(25.7 \%)$ \\
\hline Great & $19(13.6 \%)$ \\
\hline Total & $\mathbf{1 4 0}(\mathbf{1 0 0} \%)$ \\
\hline Source: Field Survey & \\
\hline &
\end{tabular}
thereby, creating entry barriers for new artisans interested in the craft.

It was found that degree of change introduced in the craft objects influences the net earnings of the artisans. As seen in Fig 1, 38.46\% of the respondents who introduced great changes either in design, form and style of the object earned in the higher net income slab of Rs. 18 ,ooo per month \& Above while another $26.92 \%$ addressing considerable modifications earn in between Rs. 12001 to Rs. 18,00o per month. Among those continuing to produce craft without any aesthetic or market consideration, $58.97 \%$ were earning only up to Rs. 6000 a month. Apart from the introduced degree of change, producers' level of dependence on intermediaries for sale of crafts and occupational style (either independent, piece-rate or wage rate) also influence net income. However, these variables are not considered for analysis in this paper. This might be the reason for which, even with considerable degree of change, $17.95 \%$ of the respondents earn only up to Rs. 6000 and $15.38 \%$ who have not introduced any modification earn in the highest income slab. 
Diagrammatic representation produced above shows that degree of change introduced in produced craft has positive impact on net income of the artisans. However, it is important to highlight here that majority of artisans (44.29\%) still lie in the income group of Rs. 6001 to Rs. 12000 while another $27.86 \%$ fall in the lowest income slab (Table 2). Only $9.29 \%$ belong to the above Rs. 18000 group.

Fig 1: Degree of Change \& Net Income

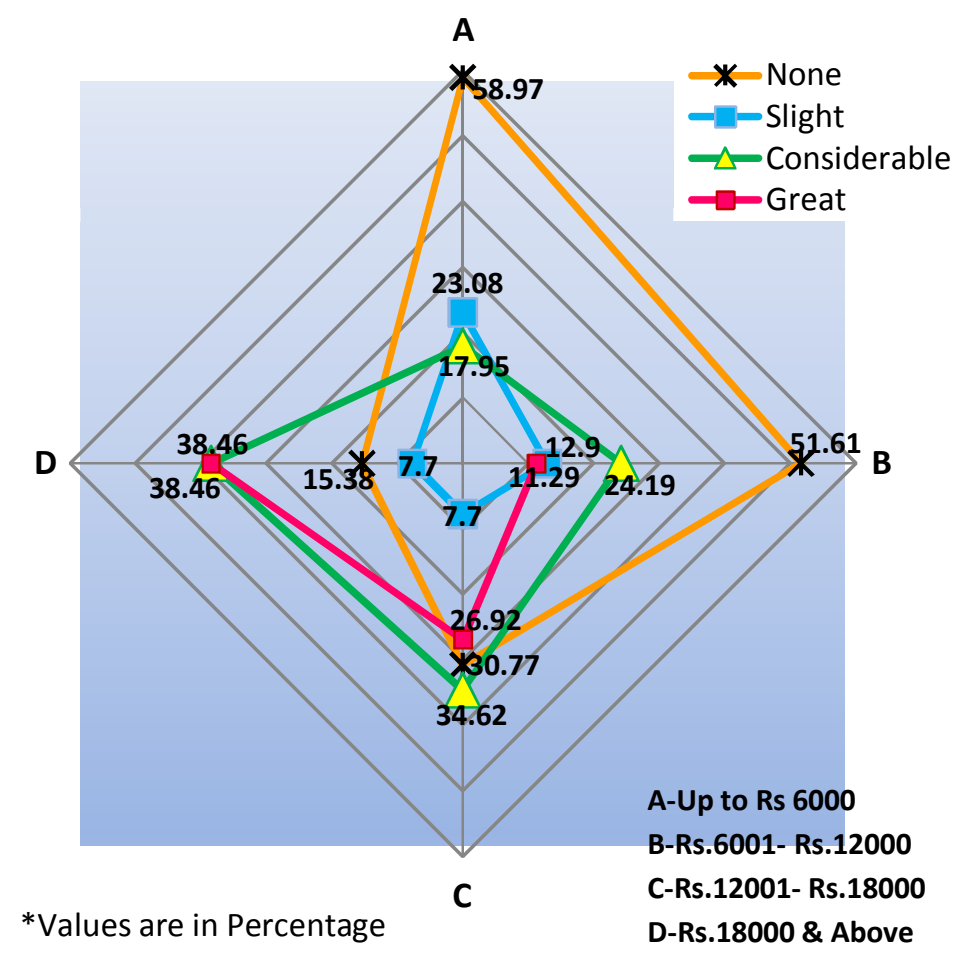

\begin{tabular}{|c|c|c|c|c|c|c|c|}
\hline \multicolumn{8}{|c|}{ Table 3: ANOVA Results for Perceived Reliability } \\
\hline \multicolumn{8}{|c|}{ RELIABLE SOURCE OF INCOME } \\
\hline $\begin{array}{l}\text { Craft } \\
\text { Genr }\end{array}$ & $\begin{array}{l}\text { Mea } \\
\text { n }\end{array}$ & $\mathbf{N}$ & Dfi & $\begin{array}{l}\text { Df } \\
2\end{array}$ & $\begin{array}{l}\text { Levene' } \\
\text { s } \quad p\end{array}$ & $\begin{array}{l}\text { ANOV } \\
\text { A (sig) }\end{array}$ & $\begin{array}{l}\text { Welch } \\
p \text { value }\end{array}$ \\
\hline $\mathrm{C}$ & 3.29 & 113 & \multirow[t]{3}{*}{2} & \multirow[t]{3}{*}{137} & \multirow[t]{3}{*}{.002} & \multirow[t]{3}{*}{.000} & \multirow[t]{3}{*}{$.000^{*}$} \\
\hline $\mathrm{D}$ & $4 \cdot 31$ & 16 & & & & & \\
\hline C \& D & 5.36 & 11 & & & & & \\
\hline Source & : Field & urve & $*$ & - & th asterisk & is consi & ared \\
\hline
\end{tabular}

To find artisans' understanding regarding reliability of the craft as a source of income, subjective assessment based on perception of the respondents are used. Perception data provides insight about individual's belief (Garner, Stinson \& Shipp, 1996; Litwin \& Sapir, 2009: 397). Perceiving craft as a reliable income source may result in future continuity of 
the craft in artisan households. It is found that income assessment of the future influences the stay in or leaving from an occupation (Dench \& Norton, 1996). Opinion about future income or economic sustainability of the craft activity is ascertained in this paper, with the help of artisans' perception about reliability of the craft as an income source.

\begin{tabular}{|l|l|l|l|l|}
\hline \multicolumn{3}{|l|}{$\begin{array}{l}\text { Table 4: Test Statistics for Reliability Perception \& } \\
\text { Opinion on Continuing the Craft in Future at 99\% } \\
\text { Confidence Interval }\end{array}$} \\
\hline \multicolumn{4}{|c|}{} & Monte Carlo Sig. (2-sided) \\
\hline Cramer's V & $\begin{array}{l}\text { Lower } \\
\text { Bound }\end{array}$ & Upper bound \\
\hline Value & Sig. & $\mathrm{N}$ & .004 \\
\hline .315 & .003 & 140 & .001 & \\
\hline \multicolumn{4}{|l|}{ Source: Field Survey } \\
\hline
\end{tabular}

For different craft genre (C, D and C \& D), as shown in Table 3, ANOVA test statistics highlight that significant differences exist in perception about craft as a reliable source of income measured on a 7-point Likert scale. Mean scores are converted into score ranges: 1-1.40 (not at all reliable), 1.40-2.8o (not reliable), 2.80-4.20 (unsure), 4.20-5.6o (Reliable), 5.60-7.0 (Totally reliable) based on scales developed by Vagias (2006) and Brown (2010). The results show that conventional craftsmen are rather unsure about the craft being a reliable source of income. Decorative genre artisans find the craft reliable. However, interestingly, artisans producing both craft genres score the highest and find the occupation totally reliable source of income.

A Monte-Carlo ${ }^{3}$ test was also conducted to find the relation between reliability perception and opinion of the artisans on continuing the craft in future. At upper bound and lower bound significance value less than o.o1 (i.e. at 99\% level of confidence), the relationship between reliability perception and opinion of the artisans on continuing the occupation is found to be significant. The relationship is moderately significant with $p$ value of .oo3 and Cramer's $\mathrm{V}^{4}$ value of 0.315 . It is important to observe that $55.6 \%$ of those who don't find the craft a reliable source of income would leave the occupation in future (Table 5). Out of those who would continue to work in the sector, $18.1 \%$ find the craft a reliable occupation. Though $50 \%$ of the respondents are unsure about the craft being a reliable source, they yet agree to resume the business in future. On-field investigation highlights

\footnotetext{
${ }^{3}$ Monte-Carlo test is a convenient test to measure the strength of association between two variables and are for most practical purposes as good as exact p values or Fisher's test results. Ref: Mehta \& Patel (1989).

${ }^{4}$ Cramer's V measures strength of association between variables. It is a post-hoc test whose value varies from o to 1 . Values between o to 0.3 shows weak to moderate association; between 0.3 to 0.6 is moderate to moderately strong association, anything above 0.6 shows strong to very strong association
} 
that the major inhibition in exiting is due to lack of other options and uncertainty in leaving the existing occupation for other work.

However, it is important to observe that $55.6 \%$ of those who don't find the craft a reliable source of income would leave the occupation in future (Table 5). Out of those who would continue to work in the sector, $18.1 \%$ find the craft a reliable occupation. Though $50 \%$ of the respondents are unsure about the craft being a reliable source, yet they agree to resume the business in future too. It is also observed that notion of continuing the craft is high among the decorative and both craft producing genre of artisans.

\begin{tabular}{|c|c|c|c|c|c|c|c|c|}
\hline \multicolumn{9}{|c|}{$\begin{array}{c}\text { Table 5: Perception about Craft Being a Reliable Source of Income \& } \\
\text { Opinion about Continuing the Craft in Future }\end{array}$} \\
\hline \multirow{3}{*}{$\begin{array}{l}\text { Perception Status } \\
\text { Not at all Reliable } \\
\end{array}$} & \multicolumn{8}{|c|}{ No. of Respondents Saying (\%) } \\
\hline & \multicolumn{2}{|c|}{ 'Yes' (\%) } & \multicolumn{2}{|c|}{ No $(\%)$} & \multicolumn{2}{|c|}{$\begin{array}{l}\text { Don't } \\
\text { Know(\%) }\end{array}$} & \multicolumn{2}{|c|}{ Total (\%) } \\
\hline & 8 & $(8.5)$ & 2 & $(22.2)$ & 11 & $(29.7)$ & 21 & $(15.0)$ \\
\hline Not Reliable & 21 & $(22.3)$ & 5 & $(55.6)$ & 17 & $(45.9)$ & 43 & $(30.7)$ \\
\hline Unsure & 47 & $(50.0)$ & 2 & $(22.2)$ & 8 & $(21.6)$ & 57 & $(40.7)$ \\
\hline Reliable & 17 & $(18.1)$ & o & (o.o) & 1 & $(2.7)$ & 18 & $(12.9)$ \\
\hline Totally Reliable & 1 & $(1.1)$ & o & (o.o) & o & (o.o) & 1 & $(0.7)$ \\
\hline \multicolumn{9}{|c|}{ Source: Field Survey } \\
\hline
\end{tabular}

Opinion about profitability of the craft activity marginally influences artisans' decision to continue or discontinue the activity in future (Table 7 ). Around $29.8 \%$ of those who find it profitable opine to stay while $66.7 \%$ who see no profit wish to leave the craft in future if options are available. Yet again, $13.8 \%$ would not leave in spite of craft being loss oriented.

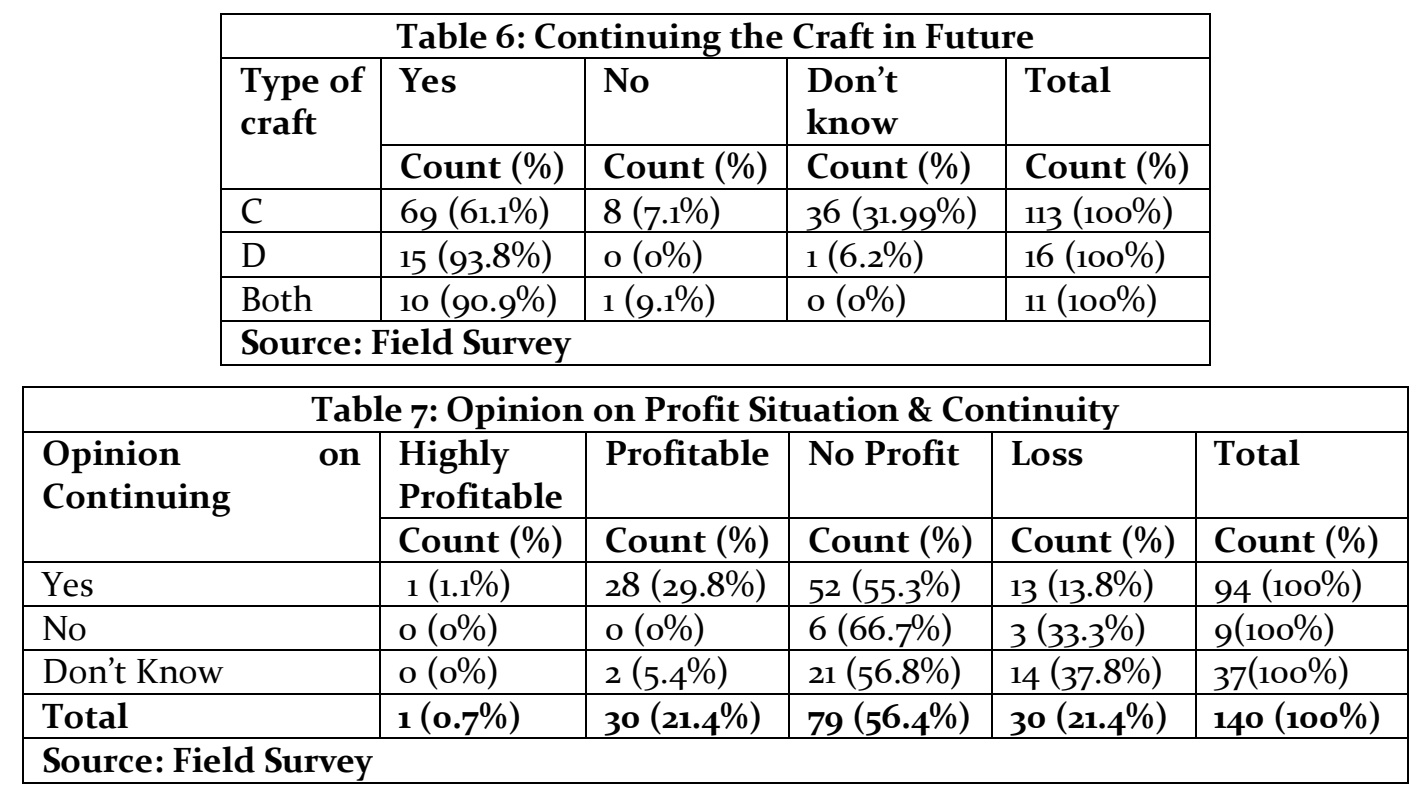




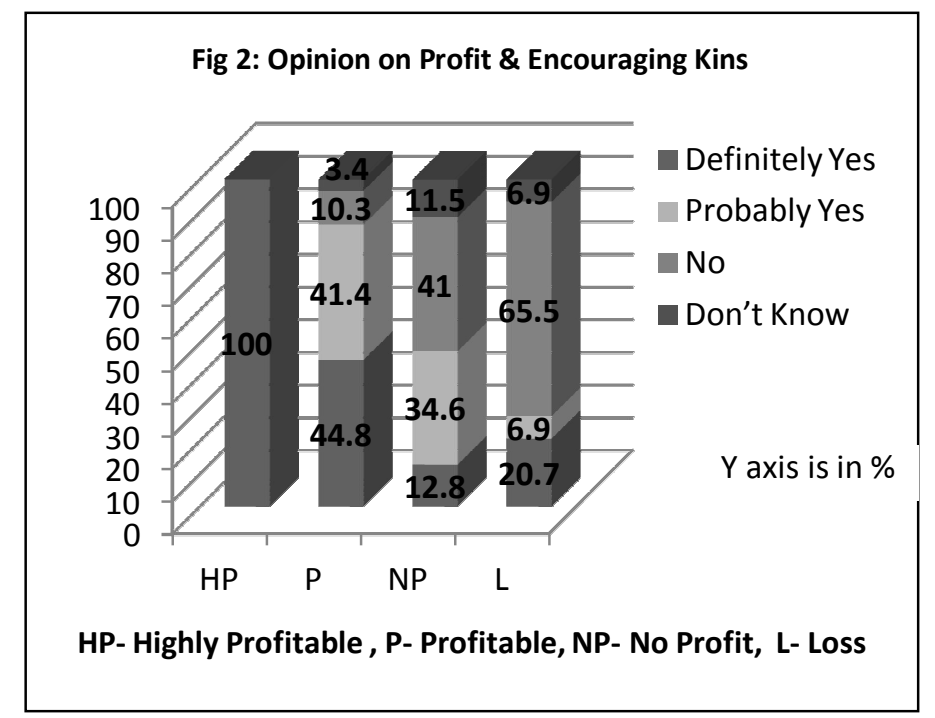

Again, opinion about the profitability of the craft also influences respondents' decision regarding encouraging children and kins to pursue the household craft activity (Fig. 2). $44.8 \%$ of the artisans who believe the activity to be profitable would definitely encourage their kins to pursue their ancestral occupation. On the other hand, $65.5 \%$ of those who find the craft to be loss oriented would never encourage their kins to pursue their occupation. It is observed that $50 \%$ of decorative craft makers find the craft profitable whereas only $10.62 \%$ of the conventional items producers agree to it. Craft Genre and its economic sustainability influences artisans' inclination towards continuation or discontinuance of the craft practice and their disposition towards persuading their family members to continue the craft in the family. It is thus observed that economic sustainability of the artisans determines future sustainability of the craft practice.

\section{Sustainability of the Craft in the Market Place}

Protagonists of authenticity and sustainability of traditional crafts argue the diminution of cultural aura surrounding crafts when it is commoditized into a salable piece (Wade, 1981). Although cultural commoditization accommodating market requirement is criticized, nevertheless, sustainability of the craft practice rests on market demand (Blumer, 2004). Artisans produce crafts that garner demand from customers. Artisans continue with tradition only till the requirement persists at household levels. In the absence of customer demand, crafts are found to be discontinued from product line. In the case of the metal craft tradition of Hajo and Sarthebari, similar situation can be noticed. Some priceless objects like jari lota, owkhulia bota, bhogjora, etc. have ceased to exist. On the other hand, craftsmen are also found to have introduced simplification in the design through minimal embossing and light chipping. Designs which were much refined and intricate are simplified through gigantism to economize time and compete in 
market place. Further, new design elements are added to the baseline designs to offer newness to the customers.

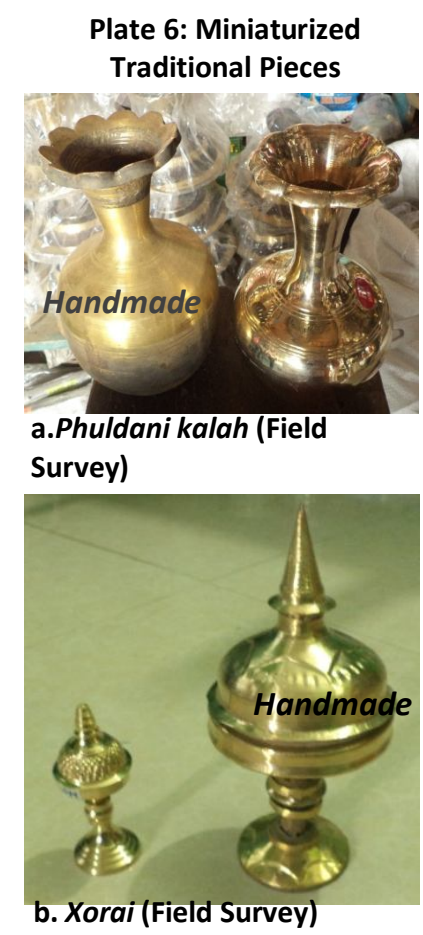

Necessary is to unearth the reasons behind the execution of new designs, simple as well as complex, and structural modifications brought by the artisan community to understand the sustainability of the craft. The first major ground was the changing iconography of the craft objects. Initially serving utilitarian and religious purposes, the metal objects like xorai, bota, kalah, lota and bati-kahi transmuted to becoming aesthetic objects fulfilling functional need. Items are now purchased for home decorations and as personal and institutional gifts. According to changing requirements, products like trays, piris plates and sof botas (small bota of 6 inches in height to serve fennel seeds) were conceptualized. Other factor that necessitated change was the continuous offloading of inexpensive, light-weight, highly polished and aesthetically brilliant craft replicas from other places into the local markets. This seems to be an example of 'decline of the aura' of artworks under the serious considerations of imitations resulting from commodification of an art (Benjamin, 1986:32). Easily detachable, smaller versions of machine finished xorais and polished phuldani kalah (see Plate 6) from markets outside Assam, created the urgency among the traditional craftsmen to respond quickly or lose the souvenir hunters segment. Refinement of the product, clastic attribute and small size is yet to be achieved fully in the handmade metal crafts of Hajo and Sarthebari, but modifications ensured a place to the local artisans in the happening purchaser base. Similarly, artisans experimented by producing small tow and khorahi for singly staying men and women of 
the cities who found it comfortable to use these utensils against the larger ones. It's accommodating size fitting easily into palm satisfied the functional need of these customers. It was also found that introduction of embossed pattern on brass soria increased its demand among women customers. Traditional artisans, to stay competitive, thus consider miniaturization and ornamentation.

Market survey among shopkeepers and marketers through qualitative interviews highlights that local customers, while buying metal objects as functional and ceremonial items for personal consumption, prefer to buy articles made locally. On the other hand, for decorative purposes and gifting requirements, they have higher tendency to consider imported imitative metal items. Decorative metal craft market is a burgeoning market in Assam though it is only marginally filled by locally made products. In realization of the preference for handmade objects over the imported ones, artisans have also considered creating innovative range of metal items. But customers' inability to differentiate between the indigenous and imported wares often lends advantage to the later. Artisans also considered using lightweight metal sheets to address weight issues and its resulting high pricing. The shift in utility of products from personal use to gifts and decorative items drives artisans to adjust their crafts to market demand. Circumstances, in fact, necessitate artisans at Hajo and Sarthebari to commit to modification of the products.

\section{Balancing Economic Sustainability and Sustainability of the Tradition of Metal Crafts}

The fact that art should remain within the confinement of local style, technique and form and for its original stated purposes is rather an over emphasized and misguided notion (Shiner, 1994). Utility of a craft changes with time and crafts failing to adhere to changing needs die. To keep the tradition of craft production sustainable in the long run, the commercialization of traditional crafts is not inappropriate. However, to keep craft objects ideal, right balance of aesthetics and tradition is required (McKean quoted in Goertzen, 2001). Artisans cannot be coerced into carving traditional motifs by sacrificing time and quantity. But, providing mechanized tools to speed up chiseling can be helpful to counter surrender of old designs. Embossing equipments to work on light metal can also restore old patterns. Again, new features like chipping of alphabetic characters symbolizing welcome, namaste and letters typifying institutional message or logos and little structural modification need not be necessarily considered as deliberate cession of traditional design components. It is mere complying with new functional requirements of the objects as gifts, mementos and ornamental objects.

Metal craft market comprises of functional products and decorative crafts. The research found that only $11.4 \%$ of the artisans comprise producers of decorative crafts. There exists 
huge potential for new artisans to enter into the decorative crafts market which at present seems to be flooded by imported items. Artisans are not averse to the idea of decorative brass and bell metal products. The feedback from the market also lends the promising information that customers prefer buying crafts made locally since it is considered traditional. But due to the unavailability of sufficient decorative items made by local artisans, customers opt for metal objects from outside. Customers also opt for imported craft items due to its design, high finish, its inexpensiveness and large variety. Artisans should be encouraged to ensure these features in their products but, at the same time, there should provision to ascertain fair prices for their produce. This can be realized by giving artisans direct excess to market. Promotion of online selling platforms under government aegis can be helpful. It can also eliminate intermediary influence.

Quality remains assured when artisans get economies of scale through use of modern tools and cheap raw materials. It is understood that at present the raw material is costing very high. Mahajans and intermediaries have controlled the raw materials market. Unwanted shortage of raw materials is created in the market due to which the artisans could work only for 18 to 20 days a month on an average. Addressing this concern can reduce the selling price as well. Simultaneously, new designs along with baseline motifs can be promoted. A sound fusion of traditional and modern designs can sustain tradition in new markets. Traditional craft practice of Sarthebari and Hajo can also be made sustainable if newer artisans can find their foothold in the decorative craft market apart from the traditional utilitarian one. The recreation of an art in innovative form is not an idea to be deplored but is a matter of a 'high-culture art' (Shanks, 1994) to be approved. Modernization in forms and styles is a genuine act of succession in tradition (Soetsu qtd in Kikuchi, 2004). As seen, higher degree of change in craft features improves income and craft genre determines artisans' perception about its reliability as an income source. Artisans pursuing decorative crafts and both types of craft, in fact, find the occupation more profitable than conventional craft producers. Yet again, it influences their decision to recommend the continuity of the craft practice in the family. The ultimate value of a craft lies not in the artifact but in the process (Botnick \& Raja, cited in Kapur \& Mittar, 2014) making the issue of originality irrelevant (Peter Dormer cited in Kikuchi, 2004). On the other hand, it can bring renewed interest and resurgence in craftsmanship (Berma, 1996).

\section{Conclusion}

The study has brought to light the notion of economic sustainability and sustainability of tradition from the perspective of the craft and the craftsmen. It is seen that the brass and bell metal crafts of Hajo and Sarthebari has been undergoing modification in its design, 
structure, and raw material. The intricacy of the carved motifs and embossing patterns has undergone great dilution and some of the old products have even ceased to exist. However, new designs elaborately chipped on the surface as well as innovation in product line is also observed along with. It is due to artisans' compulsion to remain economically productive in an era where quantity matters more to sell more and earn more. But it is also noticed that artisans involved in decorative crafts are earning well in comparison to the conventional craft makers. Craftsmen, those who are unable accommodate their crafts according to aesthetic demands struggle in economic sphere and find the occupation unreliable, with many even ready to forego their ancestral occupation in future. This brings in the issue of sustainability of the craft. However, sustainability needs to be addressed from the view point of the economic sustainability of the artisans and the sustainability of the craft in the market as well. Of course, modern elements and new components are required for the modern day customers seeking range of products. But old designs and objects show the possibility of being reproduced if artisans are given simple tools are provided to save time and effort. There is a good scope for handmade metal crafts to compete with imported wares if price, quality, variety and finish are taken care. In the western world, craft today is defined by the extraordinary attribute of being handmade. It thus provides ample market for the craft to flourish. Sustainability of traditional art encompasses the continuity of traditional products and indigenous designs while sustainability of artisans involves economic sustainability. Taken together these may create the conditions for an economically viable craft sector ensuring sustenance of tradition.

\section{References}

Allen, B. C .(1905). Assam District Gazetteers, vol.iv, Kamrup. Pioneer Press: Allahabad.

Baishya, P. (1989). Small and Cottage Industries: A Study in Assam, Manas publications: Delhi.

Ballengee-Morris, C. (2002). Cultures for Sale: Perspectives on Colonialism and Self-Determination and the Relationship to Authenticity and Tourism. Studies in Art Education. 43(3), 232-245.

Baruah, A., \& Choudhury, S.B. Roy. (1999). Gazetteer of India: Assam State. Vol i, The Editor-in-Chief, District Gazetteers, Government of Assam: Guwahati.

Benjamin, A. (1986). The Decline of Art: Benjamin's Aura. Oxford Art Journal, 9 (2), 30-35.

Berma, M. (1996). The Commercialisation Of Handicraft Production Among The Iban of Kapit Division in Sarawak, Malaysia: Constraints and Potential. Unpublished Doctoral Dissertation of University of Hull.U.K.

Blumer, T.J. (2004). Catawba Indian Pottery: The Survival of a Folk Tradition. Tuscaloosa: University of Alabama Press.

Bose, M.L.(1989). Social History of Assam. Concept Publishing Company: New Delhi.

Boynton, L. L. (1986). The Effect of Tourism on Amish Quilting Design. Annals of Tourism Research. 13, 451465.

Brown, S. (2010). ANR Program Evaluation, Iowa State University Extension, Retrieved from http://www.extension.iastate.edu/Documents/ANR/LikertScaleExamplesforSurveys.pdf 
Chotiratnapinun, T. (2009). The emergence and existence of sustainable craft practices: Case studies from Indonesia and Thailand. Making Futures. 1, 8-18. Retrieved from http://makingfutures.plymouthart.ac.uk/journalvoli/papers/treechada-chotiratanapinun.pdf

Cox, E., \& Bebbibgton, J. (n.d.). Craft and sustainable development: An investigation. Retrieved from https://www.st-

andrews.ac.uk/media/sasi/documents/Craft\%2oand\%2oSustainable\%2oDevelopment.pdf

Craft Council of India Report (2011, Agust). Ensuring sustainability of artisans and their crafts. Retrieved from http://craftscouncilofindia.org/wp-content/uploads/2014/o6/CCI-Newsletter-August-2011.pdf

Das Gupta, R. (1982). Art of Medieval Assam. Cosmo Publications: New Delhi.

Das, J. (1968). Asomor Lok-kala: Publication Board Assam: Guwahati.

Deka, A. (2012). Brass and bell metal industries in Assam: Present status and prospects for development in the changing market environment. Unpublished doctoral thesis of Gauhati University, Guwahati, Assam.

Deka, H. (1995). Oitishyapurna Pitalar silpa. In T. Tamuli \& P. Deka (Eds.), Bhortaal, Souvenir of Assam Sahitya Sabha, $61^{\text {st }}$ session, Sarthebari. 125-126.

Dench, S. \& Norton, R. (1996). Leaving Employment Early. UK: The Institute of Employment Studies, University of Sussex.

Edwards, L. R. G. (2009). Sustainability: Quality of life for artisans practicing the fair trade business model. Unpublished doctoral thesis of Prescott College, U.S. Retrieved from http://pqdtopen.proquest.com/doc/305148238.html?FMT=ABS

Gait, E. A. (1896). 'Brass and Copper Wares in Assam' 1894 in Notes on Some Industries of Assam from 1884-1895, p. 113. Compiled in the office of the secretary to the chief commissioner of Assam 1896.

Garner, T., Stinson, L. \& Shipp, S. (1996). Affordability, Income Adequacy, and Subjective Assessments of Economic Well-being: Preliminary Findings. Association for Consumer Research Conference, October 10-13, 1996, Tucson, Arizona. Retrieved from http://www.bls.gov/ore/pdf/st96o11o.pdf

Ghosh, A. (2012). Triggering innovation and creativity in traditional handicrafts sectors-An Indian perspective. Management Insight. 8 (1), 67-71.

Ghosh, Arnab. (21 July, 2016). Neglected Metal Crafts of Assam. Retrieved from http://www.nelive.in/assam/business/neglected-metal-crafts-assam

Goertzen, C. (2001). Crafts, tourism and traditional life in Chiapas, Mexico: A tale related by a pillowcase. In Carter Jones Meyer and Diana Royer (Eds.), Selling the Indian: commercializing and appropriating American Indian cultures. Tuscon: University of Arizona Press. 236-270.

Harikrishnan, U., \& Krishna, S. (2015). Promoting sustainable livelihood among tribal community through traditiona handicrafts in Wayanad district, Kerela, India. International Journal of Advanced Research. 3 (3), 620-628.

Howard, M. (2006). Indonesian Textiles from Dress to Art. In Michael Leaf (Ed.), Arts, Popular Culture \& Social change in the New Indonesia. Canada: Institute of Asian Research. 33-58.

Hutchinson, R. H. S. (1909). Eastern Bengal and Assam District Gazetteers: Chittagong hill tracts. The Pioneer Press: Allahabad.

Kalita, B. (2007). A geographical analysis of Bell-metal industry in Sarthebari, Assam. Unpublished Doctoral dissertation of Gauhati University, Guwahati.

Kapur, H., \& Mittar, S (2014). Design intervention and craft revival. International Journal of Scientific and Research Publications, 4 (10), 1-5.

Kikuchi, Y. (2004). Japanese Modernisation and Mingei Theory: Cultural nationalism and oriental orientation, London and New York: Routledge Curzon.

Laduke, B. (1981). Traditional women artists in Borneo, Indonesia and India. Women's Art Journal. 2(1), 1720.

Litwin, H., \& Sapir, E. V. (2009). Perceived Income Adequacy Among Older Adults in 12 Countries: Findings From the Survey of Health, Ageing, and Retirement in Europe , The Gerontologist, 49 (3), 397406.

Makhitha, K. C. (2013). An investigation into buyer behavior of craft retailers in South Africa. Unpublished doctoral thesis of University of Pretoria, South Africa. 
Mehta, C. R., \& Patel, N. R. (1989). IBM SPSS Exact Tests. IBM: U.S.

Minca, C., \&Oakes, T. (Ed) (2006). Eds. Travels in paradox: Remapping tourism. Oxford: Rowman \& Littlefield Publishers Inc.

Mohapatra, R. C. (2005). Changing patterns in the applique craft of Pipili. Orissa Review, 66-67. Retrieved January 10, 2013, from http://orissa.gov.in/e-

magazine/Orissareview/dec2005/engpdf/changing_patterns_in_the_applique_craft_of_pipili.pdf

Mohapatra, H. K. (2008). Cultural resurgence in Orissa during the post independence era. Orissa Review, 2008. 1-10.

O'Connor, C. K. (2012). Ethnic tourism advertisements: The power dynamic and its effect on cultural representations in the "Kingdome of Daughters". Bachelor thesis, University of Pittsburgh. U.S. Retrieved from http://d-scholarship.pitt.edu/13535/1/OConnor_BPhilETD_2012.pdf

Patra, S.C., \& Vachani, A. (Ed.) (2012). Socio-Economic Profile of Rural India. Vol II. New Delhi: Concept Publishing

Popelka, Cheryl Ann and Mary Ann Littrell. 1991. Influence of tourism on handcraft evolution. Annals of tourism research. 18, 392-413.

Ratnam, A. (2011). Traditional occupations in a modern world: Implications for career guidance and livelihood planning. International Journal of Education and Vocational Guidance. 11, 95-109.

Rowlands, M. (2002). The power of origins: Questions of cultural rights. In The material culture reader, ed. V. Buchli, 115-133. Oxford \& New York: Berg.

Sahay, M. (2015). Turnaround Strategy For Brass And Bell Metal Industry In Assam, India. International Journal of Innovation and Applied Studies. 11 (1), 191-196.

Sarma, S. (1989). A socio-economic and cultural history of Medieval Assam (1200 A.D. - 180o A.D.). Bina Library: Guwahati.

Shiner, L. (1994). 'Primitive fakes', "Tourist Art," and the Ideology of Authenticity. The Journal of Aesthetics and Art Criticism, 52 (2), 225-234

Soteriou, A. (1986). Papermaking: Finding a lost tradition. Craft International. 20-21.

Tamuli, T. (2009). Sarthebarir kah shilp. In Assam Samabay kahar sangh ltd., Sarthebari Maharajaat Jayanti Udyapan Smritigranth, 2009. Borkah. 39-41.

Vadakepat, V. M., \& Khateeb, F. Al (2012). Globalizing rural markets: Evidence from handmade traditional product markets Global Journal of Business Research. 6 (4).

Vagias, W. M. (2006). Likert-type scale response anchors. Clemson International Institute for Tourism \& Research Development, Department of Parks, Recreation and Tourism Management. Clemson University.

Waterbury, R. (1989). Embroidery for tourists: A contemporary putting-out system in Oaxaca, Mexico. In A. B. Weiner and J. Schneider (Eds.), Cloth and Human Experience. Washington DC: Smithsonian Institute, 243-271.

Wilkinson-Weber, C.(2004). Women, work and the imagination of craft in South Asia. Contemporary South Asia, 13:3, 287-306

Wolff. J. (1981). The social production of art. London: MacMillan, 1981.

Reisinger, Y., \& Steiner, C. J. (2006). Reconceptualizing object authenticity. Annals of Tourism Research, 33(1), 65-86.

Terziyska, I. (2014). Interpretations of authenticity in tourism. Science $\mathcal{E}$ Research, 4, n.p.

Lakhimi Jogendranath Chutia is a Research scholar in the Dept. of Business Administration, Tezpur University, Assam. Her area of interest surrounds the traditional crafts, its sustainable development, and marketing. She is pursuing her research with respect to the commercialization of the traditional crafts of Assam

Mrinmoy K Sarma is a senior Professor in the Dept. of Business Administration, Tezpur University, Assam. He takes keen interest in the traditional craft sector of Assam. He has written few books on tourism and crafts and has published many research articles in reputed journals. 